\title{
THE HIGH-ENERGY IRRADIATION AGEING OF REINFORCED ELASTOMERS BASED ON RUBBER BLENDS
}

\author{
Gordana Marković ${ }^{\text {, Milena Marinović-Cincovićé }}{ }^{\text {, }}$ \\ Vojislav Jovanović3 3 , Suzana Samaržija-Jovanovićc3, Ljiljana Tanasić4, \\ Radmila Radičević5, Jaroslava Budinski-Simendićc ${ }^{*}$
}

\author{
1Tigar A.D., Pirot, Serbia \\ ${ }^{2}$ University of Belgrade, Institute of Nuclear Science Vinča, Serbia \\ 3 University of Priština, Faculty of Natural Science and Mathematics, Kosovska Mitrovica, Serbia \\ 4High Agricultural School of Vocational Studies, Šabac, Serbia \\ 5University of Novi Sad, Faculty of Technology, Serbia
}

\begin{abstract}
Elastomers are very often used in severe environments, for instance, in nuclear power plants, where they may be degraded by high-energy radiation and heat. The ageing behaviour of materials used in different equipments is very important. Elastomers based on chlorosulfonated polyethylene (CSM) are used for cable jacketing materials and have excellent radiation resistance needed in nuclear power stations. In the current work, the influence of $\gamma$ irradiation dose $(100,200$ and $400 \mathrm{kGy})$ on the ageing of reinforced blends based on CSM, styrene butadiene rubber (SBR) and natural rubber (NR) has been evaluated. The content of silica in CSM/SBR and CSM/NR rubber blends was varied. The curing behavior of compounds was estimated using the oscillating disk reometer. The irradiation of nano composites has been performed in air in the Co 60 radiation sterilization unit with the dose rate of $10 \mathrm{kGy} \mathrm{h}^{-1}$. The thermal properties were studied by thermogravimetric test. The mechanical properties (hardness, modulus at $100 \%$ elongation, tensile strength and elongation at break) were determined before and after irradiation. A decrease in the elastic modulus and in the strain at break has been observed with increasing irradiation. At higher doses, the network chain scissions become the main degradation process, the cross-linked topology becomes irregular, and material contains more and more weak zones, which deteriorate the ultimate properties.
\end{abstract}

Key words: Rubber blend, filler, cross-linking, nano-composites

DOI: $10.21175 /$ RadProc.2016.23

\section{INTRODUCTION}

The nuclear power industry uses rubbers for many sealing applications such as airlock doors, hatches, pool gates, vibration damping. Made from macromolecules from which they derive their names, rubbers also contain other materials and various additives. For selecting an elastomer seal formulations without understanding the terminology of network precursor manufacturer can fabricate the wrong type of material for a particular application. To prevent this it is obligate to define the material's compatibility with the media being sealed and the compressibility requirements for special application. Blending of two or more types of rubber is a useful technique for preparing materials with properties superior to those of individual constituents. Moreover, each kind of network precursor in the blend has its own advantages and specific application due to its chemical configuration. Hence, it is economically easier to blend more than one type of rubber having the desired properties rather than chemically creating of a new elastomer. Natural rubber (NR) and styrene-butadiene rubber (SBR) was blended for a long time for these reasons. SBR represents the synthetic rubber that is still widely used for manufacturing a car tyre treads, automotive parts, technical parts, cable insulations, shoe sole, molded goods ets. SBR is a random copolymer, does not crystallize on stretching. NR is an hydrocarbon polymer that naturally occurs as a milky colloidal suspension, or latex, in the sap of some plants, and is categorized as a radiation cross-linking type of network precursor. Chlorosulfonated polyethylene (CSM) is superior to other rubbers in its resistance to the effects of ozone and inorganic acids, such as chromic, nitric, sulfuric, and phosphoric acids, as well as to the effects of concentrated alkalis, chlorine dioxide, and hydrogen peroxide. The temperature range for its most efficient use is from $-60^{\circ}$ to $180^{\circ} \mathrm{C}$. The groups $-\mathrm{SO}_{2} \mathrm{Cl}$ and labile chlorine atoms participate in the cross-linking of CSM. Properly formulated elastomer based on this network precursor offer good dynamic properties and strong adhesion to various substrates, but due to its poor compression set, thus the dynamic sealing applications are not recommended. This rubber has excellent irradiation resistance needed in nuclear power stations. The

jarkamer@gmail.com 
phenomenon of reinforcement by active fillers is unique to rubbers. The reinforcement ability of fillers is influenced by three primary characteristics: particle size, polymer-filler bonding and the particle complexity $[1,2]$. Radiochemical studies on crosslinking or ageing of polymers are important for designing advanced elastomeric materials. In the present work the goal was to investigate the influence of $\gamma$-irradiation dose on ageing of silica reinforced rubber blends (CSM/SBR, CSM/NR).

\section{EXPERIMENTAL}

\subsection{Materials}

Natural rubber was supplied by Dow chemical, USA. Its cis-1,4 content was $97 \%$. Styrene-butadiene rubber (SBR 1502) with 23.6 wt\% of styrene content was used. Chlorosufonated polyethylene (CSM, Hypalon 40S) was obtained from DuPont. The rubbers were used as delivered. Nano silica filler (Ultrasil WN3, Degussa) has $22 \mathrm{~nm}$ average size of primary particles. The network precursor ratio was 80:20 (w/w).

\subsection{Compounding and Cross-linking}

The rubbers were separately pre-masticated for about 1 min each, keeping a tight nip gap. The mixing of the rubbers and fillers was per formed on a two roll mill at $50^{\circ} \mathrm{C}$. The vulcanization characteristics of compounds were carried out using an oscillating disc reometer (Monsanto 100) at $160^{\circ} \mathrm{C}$. The cross-linking was carried out at $160^{\circ} \mathrm{C}$ in an electrically heated hydraulic press. The scorch time $\left(t_{\mathrm{s} 2}\right)$, the optimum cure time $\left(t_{\mathrm{cgo}}\right)$, the curing rate index $(C R I)$, and maximum torque $\left(M_{\mathrm{h}}\right)$ were determined from the obtained curves.

\subsection{Gamma Irradiation}

Irradiations has been performed in air in the Co 60 radiation sterilization unit at the Vinča Institute of Nuclear Sciences with the dose rate of $10 \mathrm{kGyh}^{-1}$ and total absorbed dose of 100, 200, and $400 \mathrm{kGy}$.

\subsection{Sample Characterizations}

Tensile tests were performed on dumbbell samples that were cut from sheets ( $2 \mathrm{~mm}$ thick). The tensile strength and the elongation at break were determined at room temperature using an universal tensile testing machine (Zwick 1425). The given results are the mean value of three specimens. Samples with flat surface were cut for hardness test (Durometer Model 306L Type A). Equilibrium swelling was carried out on uniform circular samples by the immersion method [3] in toluene. The samples were allowed to swell for two days until the equilibrium was reached. The swelling degree $Q$ was calculated as:

$$
Q=\frac{m-m_{0}}{m_{0}} \frac{\rho_{n}}{\rho_{m}}
$$

where $m$ and $m_{0}$ are the weights of the swelled and dried sample; $\rho_{2}$ and $\rho_{1}$ are the density of the sample and the solvent.
Table 1. Formulations of compounds based on CSM/NR and CSM/SBR rubber blends

\begin{tabular}{|l|c|c|c|c|c|c|}
\hline \multirow{4}{*}{ (phr) } & \multicolumn{7}{|c|}{ Rubber blend samples } \\
\cline { 2 - 7 } & \multicolumn{7}{|c|}{ CSM/NR } \\
\cline { 2 - 7 } & 1 & 2 & 3 & 4 & 5 & 6 \\
\cline { 2 - 7 } & CSM/SBR \\
\cline { 2 - 7 } & 7 & 8 & 9 & 10 & 11 & 12 \\
\hline Silica & 0 & 20 & 40 & 60 & 80 & 100 \\
\hline Diethylene glycole & 0 & 0.2 & 0.4 & 0.6 & 0.8 & 1.0 \\
\hline
\end{tabular}

*The content ingredients was: tetramethyl thiuramdisulfide, TMTD (1 phr); N-cyclohexyl-2-benzothiazolesulfonamide, CBS (1 phr); magnesium oxide (4 phr); sulfur (1.5 phr); zinc oxide $5 \mathrm{phr}$; stearic acid (2 phr); naphthenic oil (10 phr).

\subsection{Gamma irradiation}

Irradiations has been performed in air in the Co 60 radiation sterilization unit at the Vinča Institute of Nuclear Sciences with the dose rate of $10 \mathrm{kGyh}^{-1}$ and total absorbed dose of 100, 200, and $400 \mathrm{kGy}$.

\section{RESULTS AND DISCUSSION}

The cure characteristics of the composites based on rubber blends are summarized in Table 2. The values for curing data depend mainly on the nature of the network precursors employed in the blend. The shorter $M_{1}$ and higher $\Delta M$ for filled rubbers are indicators for stronger interactions between nano particles and polymer matrix. According to silica surface [4], the scorch time $\left(\mathrm{t}_{\mathrm{s} 2}\right)$ of reinforced CSM/SBR is higher than for $\mathrm{CSM} / \mathrm{NR}$, but the optimum curing time $\left(\mathrm{t}_{\mathrm{cgo}}\right)$ is lower. The retardation effect for rubber blend curing observed for compounds with silica can be attributed to the hydroxyl groups at the filler surface. The cure rate index (CRI) was calculated as:

$$
\mathrm{CP}=100 /\left(\mathrm{tat}-\mathrm{t}_{\mathrm{a}}\right)
$$

It is obvious that CRI value is significant higher for CSM/SBR rubber blend. Also, filled rubbers have higher CRI than unfilled. For both rubber blend composites the CRI values are increasing with silica content. This effect supports the activation of the cure reaction up to the nano silica content of $60 \mathrm{phr}$. At higher loadings, a deactivation of the cure process was observed. This can be explained by the fact that for the particular rubber blend with critical filler volume fraction there is the tendency of the filler agglomeration. Another procedure to evaluate the reinforcing effect of active filler is the $\alpha$ value as proposed in [5] where following expression was employed:

$$
a=\left(M_{\max }-M_{\max }^{0}\right) / M_{\max }^{0}
$$

where $M_{\max }$ denote the maximum torque of the filled matrix and the unfilled rubber blend, and $\alpha$ is the relative increase of the maximum torque that should increase, when the silica is added. The ratio between the increase in torque of the filled compound and the one of unfilled was proportional to the filler loading:

$$
\frac{M_{\max }-M_{\min }}{M_{\max }^{\mathrm{D}}-M_{\min }^{\mathrm{D}}}-1=a \frac{m_{f}}{m_{q}}
$$


were $M_{\max }-M_{\min }$ are the maximum change in torque during vulcanization; $m_{\mathrm{r}}$ is the mass of rubber, $m_{\mathrm{f}}$ of filler in the compound.

Table 2. The curing characteristics of nano-silica filled samples based on CSM/NR and CSM/SBR

\begin{tabular}{|c|c|c|c|c|c|c|c|}
\hline \multirow{2}{*}{ No. } & \multicolumn{7}{|c|}{ Cure characteristics } \\
\cline { 2 - 9 } & $\begin{array}{c}\mathrm{M}_{\mathrm{l}}, \\
\mathrm{dNm}\end{array}$ & $\begin{array}{c}\mathrm{M}_{\mathrm{h},} \\
\mathrm{dNm}\end{array}$ & $\begin{array}{c}\Delta \mathrm{M}, \\
\mathrm{dNm}\end{array}$ & $\begin{array}{c}\mathrm{t}_{\mathrm{s} 2}, \mathrm{~m} \\
\text { in }\end{array}$ & $\begin{array}{c}\mathrm{t}_{\mathrm{cgo}}, \\
\mathrm{min}\end{array}$ & CRI & $\alpha$ \\
\hline 1 & 5 & 40 & 35 & 11 & 38 & 3.7 & - \\
\hline 2 & 6 & 42 & 37 & 11 & 38 & 3.7 & 0.05 \\
\hline 3 & 6 & 45 & 39 & 12 & 37 & 4.0 & 0.13 \\
\hline 4 & 8 & 46 & 38 & 12 & 36 & 4.2 & 0.15 \\
\hline 5 & 8 & 47 & 39 & 12 & 36 & 4.2 & 0.18 \\
\hline 6 & 8 & 47 & 39 & 12 & 36 & 4.2 & 0.18 \\
\hline 7 & 6 & 39 & 33 & 12 & 37 & 4.0 & - \\
\hline 8 & 7 & 41 & 34 & 12 & 37 & 4.0 & 0.05 \\
\hline 9 & 7 & 45 & 38 & 12 & 36 & 4.2 & 0.15 \\
\hline 10 & 8 & 48 & 40 & 13 & 36 & 4.3 & 0.23 \\
\hline 11 & 8 & 49 & 41 & 13 & 36 & 4.3 & 0.26 \\
\hline 12 & 8 & 49 & 41 & 13 & 36 & 4.3 & 0.26 \\
\hline
\end{tabular}

The higher values of $\alpha$ indicate better interaction filler with rubber. The relative torque shows an increasing value as a function of the incorporation of silica up to $80 \mathrm{phr}$. The tensile strength (Figure 1a and 1b) increases with increasing dose for the both rubber blends, and the optimum tensile strength shifts to a lower dose as the silica content is increased.

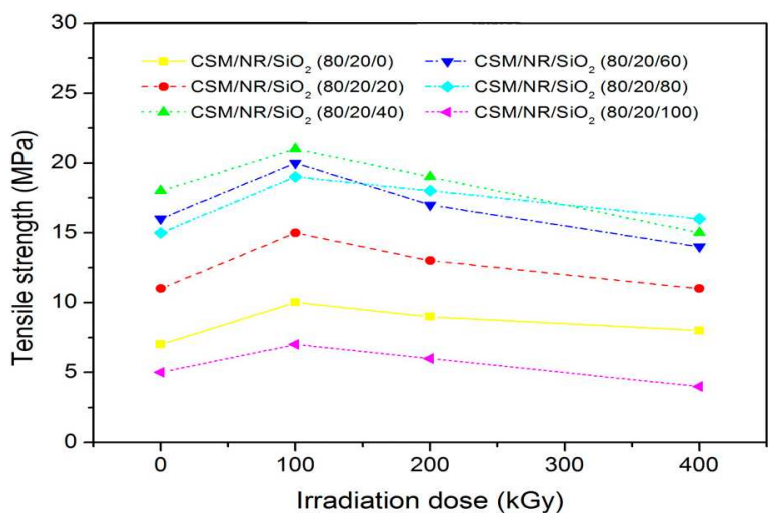

a)

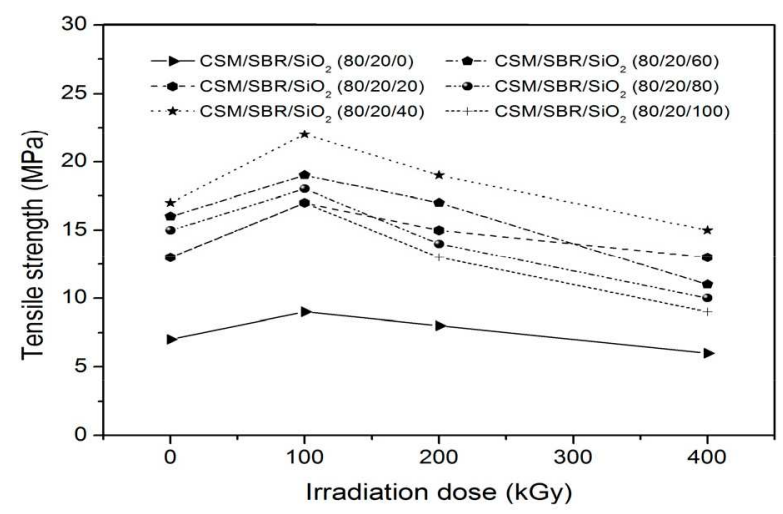

b)

Figure 1. The effect of irradiation dose on tensile strength of nano-composites based on a) CSM/NR and b) CSM/SBR rubber blend with different content of silica
At a relatively higher radiation (200 and $400 \mathrm{kGy}$ ) oxidative degradation is induced. The tensile strength for $\mathrm{CSM} / \mathrm{NR}$ with $60 \mathrm{phr}$ silica was $20 \mathrm{MPa}$ at $100 \mathrm{kGy}$, $17 \mathrm{MPa}$ at $200 \mathrm{kGy}$, and $14 \mathrm{MPa}$ at $400 \mathrm{kGy}$; for $\mathrm{CSM} / \mathrm{SBR}$ with the same silica content tensile strength was $19 \mathrm{MPa}$ at $100 \mathrm{kGy}, 17 \mathrm{MPa}$ at $200 \mathrm{kGy}$, and 11 $\mathrm{MPa}$ at $400 \mathrm{kGy}$. The addition of silica caused the increase in tensile strength. As observed, nano-silica can also acts as a sensitizer in radiation-induced crosslinking reactions [6]. Both NR and SBR rubbers are categorized as predominantly radiation cross-linkable network precursors, which would account for the increase in tensile strength values with the dose up to $100 \mathrm{kGy}$. The different type of groups that exist on its surface would then participate in physical as well as chemical bond formation at the interface between the filler and rubber matrix, on irradiation. Fig. $2 a$ and $2 b$ shows the variation of elongation at break for rubber blends with different silica content.

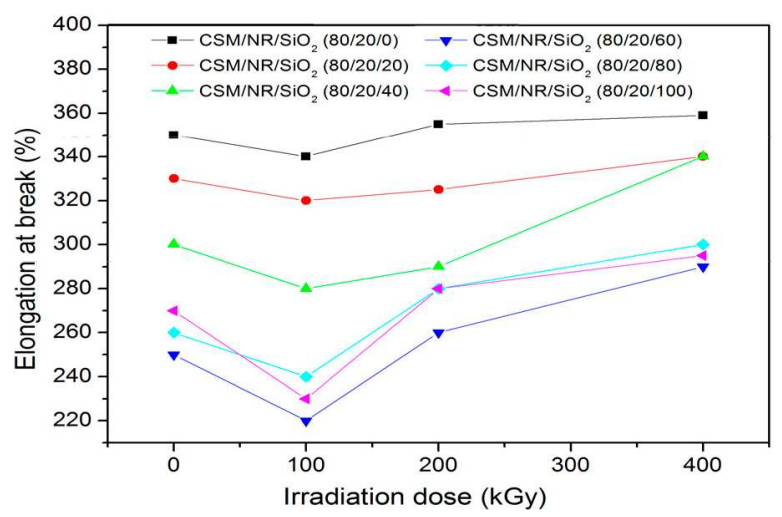

a)

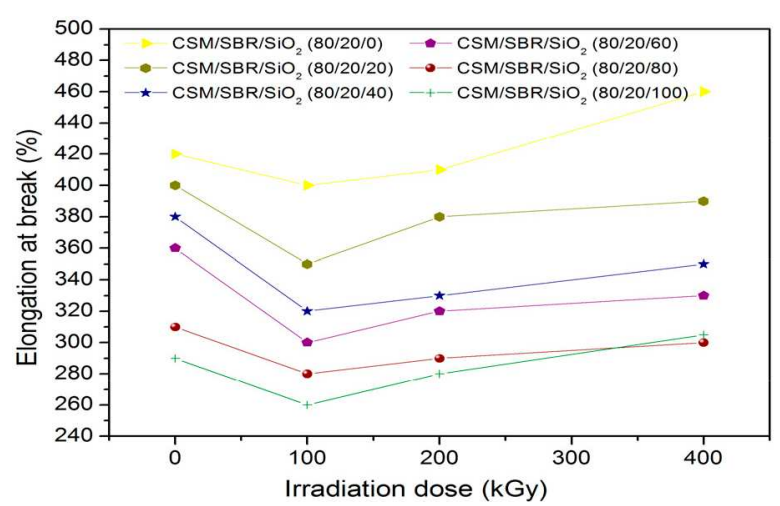

b)

Figure 2. The effect of irradiation dose on elongation at break for nano-composites based on a) CSM/NR and b) CSM/SBR with different content of silica

The decrease of this value for rubber blends exposed to higher irradiation dose is explaining by an additional bonding between the filler and rubber due to the large number of free radicals formed under irradiation. The hardness values for the blends are shown in Figs.3a and 3b. It was observed that the hardness is increasing with the increasing silica content. For composites based on polar rubbers such as CSM, the occurrence of chemical reactions with silica surface functional groups are more probable. The volume swell ratio (Q) was measured to characterize 
the cross-linking degree. The low Q value refers to high cross-linking degree.

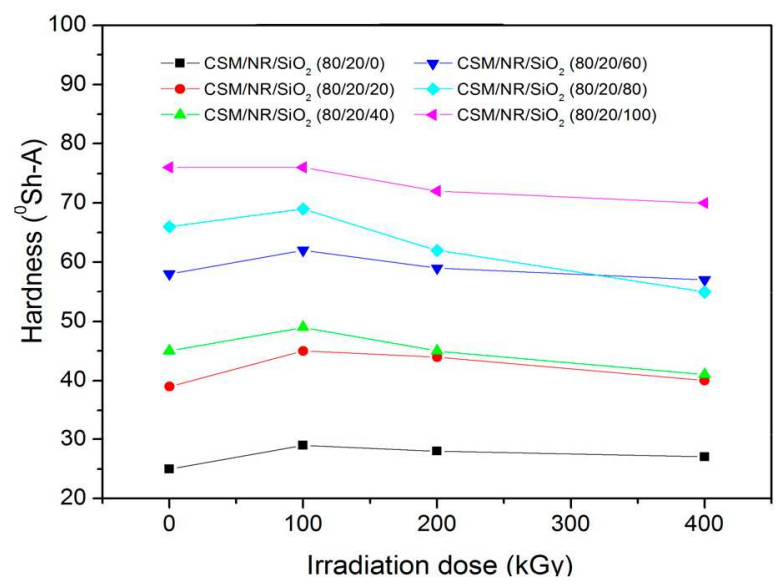

a)

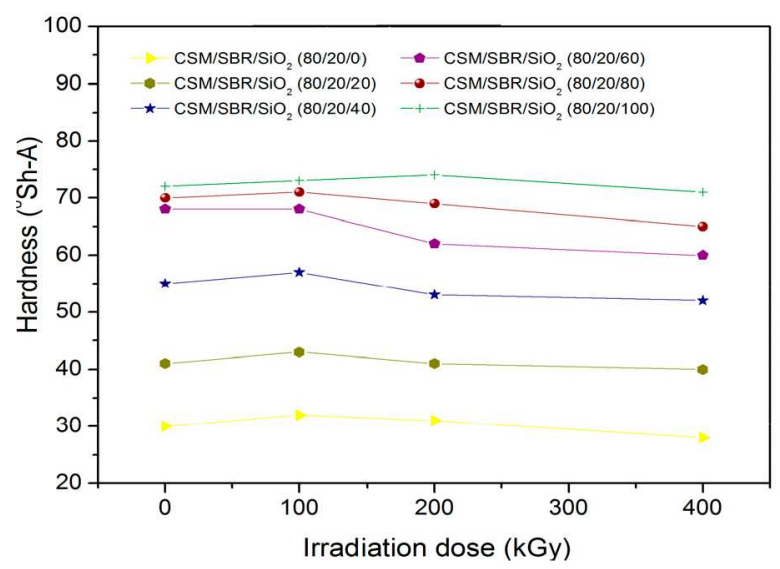

b)

Figure 3. The effect of irradiation dose on hardness of nanocomposites based on a) CSM/NR and b) CSM/SBR rubber blend with different content of silica

Figs. $4 \mathrm{a}$ and $4 \mathrm{~b}$ are showing that the swelling degree of unfilled rubber blend, increases sharply with the increase of the doses up to $100 \mathrm{kGy}$ and thereafter the plateau is observed. It is apparent here that crosslinking reactions are induced at a lower dose when silica is present in the blends. These data clearly indicate that prepared composites have better swelling resistance than unfilled rubber blend.

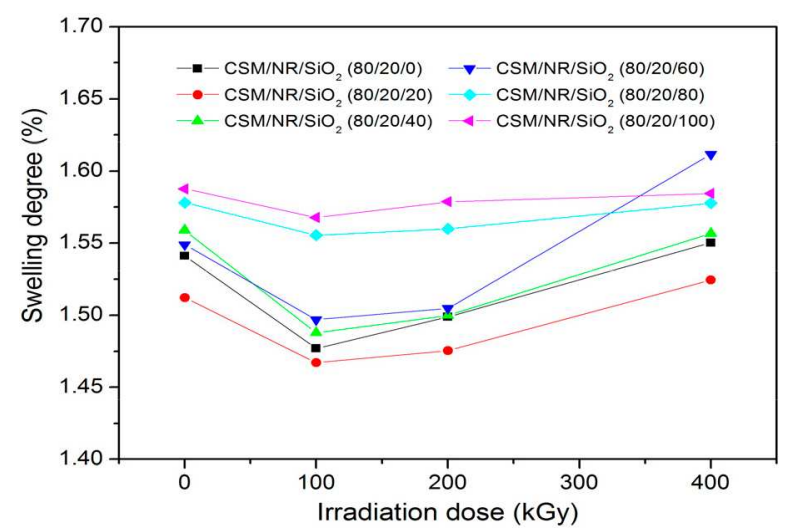

a)

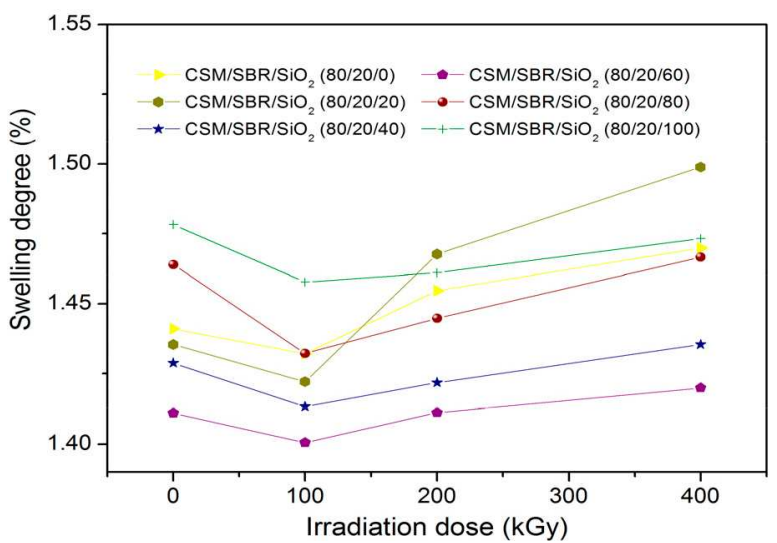

b)

Figure 4. The effect of irradiation dose on swelling of nanocomposites based on a) CSM/NR and b) CSM/SBR rubber blend with different content of silica

\section{CONCLUSIONS}

The influence of nano-silica particles on the gamma irradiation ageing of CSM/NR and CSM/SBR rubber blends was investigated. The values of tensile strength and hardness increased, but elongation at break decreased with increasing irradiation dose. The use of active nano-silica particles improved the mechanical properties and swelling resistance in toluene for all samples after irradiation. The increased radical recombination is likely to generate strong chemical linkage with an increase of the radiation dose. At higher filler content a chain scission process becomes more predominant than cross-linking.

Acknowledgement: Financial support for this study was granted by the Ministry of Science and Technological Development of the Republic of Serbia (Projects Numbers 45022 and 45020).

\section{REFERENCES}

1. G. Marković, S. Samardžija-Jovanović, V. Jovanović and M. Marinović-Cincović, "Thermal Stability of CR/CSM Rubber Blends Filled with Nano- and Micro-Silica Particles," J. Therm. Anal. Cal., vol. 100, no. 3, pp. 881888, June 2010

2. G. Marković, M. Marinović-Cincović, V. Jovanović, S. Samardžija-Jovanović and J. Budinski-Simendić, "The Effect of Gamma Radiation on the Ageing of Sulfur Cured NR/CSM and NBR/CSM Rubber Blends Reinforced by Carbon Black," CICEQ, vol. 15, no. 4, pp. 291-298, 2009

3. $\mathrm{H}$. Wu et al., "New Understanding of Morphology Evolution of Thermoplastic Vulcanizate (TPV) during Dynamic Vulcanization," ACS Chem. Eng., vol. 3, no. 1, pp. 26-32, 2015

4. N. Sombatsompop and C. Kumnuantip, Rheology, Cure Characteristics, Physical and Mechanical Properties of Tire Tread Reclaimed Rubber/Natural Rubber Compounds, J. App. Polym. Sci., vol. 87, no. 10, pp. 1723-1731, Mar. 2003

5. S. Samaržija-Jovanović, V. Jovanović, G. Marković, S. Konstantinović and M. Marinovic-Cincović, "NanoComposites Based on Silica Reinforced EthylenePropylene-Diene-Monomer/Acrylonitrile Butadiene Rubber Blends," Compos. B: Eng., vol. 42, no. 5, pp. 1244-1250, July 2011 